\title{
Pengaruh Penerapan Remote Electronic Voting System (REVS) Terhadap Tingkat Partisipasi Pemilih Menggunakan Model UTAUT
}

\author{
Aji Setiawan \\ Program Studi Teknik Informatika, Universitas Darma Persada \\ J1. Raden Inten II, Kota Jakarta Timur, Kode Pos 13450, Jakarta, Indonesia \\ E-mail : aziesetiawan@gmail.com
}

\begin{abstract}
Abstrak
Penggunaan sistem informasi penunjang seperti $e$-filling, $e$-ktp, e-procurement dan sebagainya yang sudah mulai diperkenalkan bagi masyarakat luas maupun individu-individu tertentu oleh pemerintah sudah cukup baik, namun sangat jauh berbeda bila kita cermati bagaimana upaya dan usaha pemerintah mendukung demokrasi dalam proses pemilihan umum dengan menggunakan $e$-voting, padahal saat ini memiliki banyak permasalahan yang memicu konflik-konflik horizontal di tengah masyarakat akibat proses pemilihan umum. Penelitian ini memiliki tujuan (1) memberikan bukti empiris tentang pengaruh $e$-voting yang diterapkan pada tingkat partisipasi yang didasarkan pada model teknologi ditawarkan, (2) menentukan pengaruh langsung variabel prediktor termasuk performance expectancy, effort expectancy, facilitating condition, mobility, security \& privacy dan experience untuk tingkat partisipasi masyarakat. Faktor yang diteliti dalam penelitian ini menggunakan model UTAUT. Hasil penelitian menjelaskan bahwa penerimaan teknologi REVS dipengaruhi oleh variabel performance expectancy, dimana pemilih berharap agar rekapitulasi hasil suara bisa tepat dan akurat. Selanjutnya adalah variabel mobility dimana pemilih percaya mereka dapat melakukan pemilihan dimana pun mereka berada, tidak dihalangi oleh aturan yang mengharuskan mereka untuk menghadiri di tempat tertentu, sedangkan untuk security \& privacy pemilih menginginkan sistem pemilu yang aman dari ancaman baik internal dan eksternal dan tetap menjaga nilai-nilai privasi.
\end{abstract}

Kata Kunci: Sistem Informasi, Remote Electronic Voting System (REVS), Unified Theory of Acceptance and Use of Technology (UTAUT).

\begin{abstract}
Today the use of information systems support such as e-filing, e-ID card, e-procurement and so forth that have been introduced for the public and certain individuals by the government has been quite good, but very much different when we look at how the efforts and the government's efforts to support democracy in the electoral process by using e-voting, but today has many problems that trigger horizontal conflicts in the society due to the electoral process. This research has a purpose (1) provides empirical evidence about the influence of e-voting is applied at a level of participation that is based on a model of technology offered, (2) determining the direct influence of predictor variables including performance expectancy, effort expectancy, facilitating condition, mobility, security \& privacy and experience to the level of community participation. Factors to be examined in this study using a model UTAUT. The results of the study explained that the technology acceptance REVS expectancy is influenced by variable performance, which voters hope that the recapitulation of the sound can be precise and accurate. Next is the variable mobility of voters believe they are able to vote wherever they are, are not hindered by rules that require them to attend a cpertain place, while for the security and privacy of voters want the electoral system safe from threats both internal and external, and keep the values the value of privacy.
\end{abstract}

Keywords: Information systems, Remote Electronic Voting System (REVS), Unified Theory of Acceptance and Use of Technology (UTAUT). 


\section{PENDAhuluan}

Perkembangan era teknologi informasi yang terus berubah dengan cepat menjadikan keharusan bagi setiap perusahaan swasta maupun pemerintah dapat terus mengikuti pola perkembangan teknologi. Khusus bagi pemerintah sudah banyak penggunaan sistem informasi seperti e-filling, e-ktp, e-procurement dan sebagainya yang sudah mulai diperkenalkan bagi masyarakat luas maupun individu-individu tertentu, namun sangat jauh berbeda bila kita cermati bagaimana upaya dan usaha pemerintah mendukung demokrasi dalam proses pemilihan umum dengan menggunakan e-voting, padahal saat ini memiliki banyak permasalahan yang memicu konflik-konflik horizontal di tengah masyarakat akibat proses pemilihan umum.

Pertimbangan utama yang mendasari penerapan $e$ voting yaitu adanya sejumlah manfaat dan perkembangan yang cepat disertai kondisi para penduduk yang sudah melek teknologi (Edi \& Fereshi, 2010). Berdasarkan latarbelakang itulah pada penelitian ini mencoba menggali hubungan penerimaan teknologi dalam demokrasi dengan model REVS yang telah diuji coba dalam pemilihan kepala desa Kutabaru, kabupaten Tangerang berdasarkan faktor penerimaan UTAUT. Dimana wilayah kabupaten Tangerang termasuk salah satu daerah dengan tingkat homogenitas pendidikan dan latar belakang yang berbeda.

\section{TINJAUAN PUSTAKA}

\section{Sistem Informasi}

Menurut O'Brian dikutip oleh Yakub (2012:17) pada buku Pengantar Sistem Informasi,sistem informasi (information system) merupakan kombinasi teratur dari orang-orang, perangkat keras, perangkat lunak, jaringan komunikasi, dan sumber daya data yang mengumpulkan, mengubah, menyebarkan informasi dalam sebuah organisasi.

\section{Remote Electronic Voting System (REVS)}

Paatey dan Ofori mendefinisikan $e$-votings : meant to phase out outdated paper ballot, punched cards and other mechanical voting systems with paperless electronic or online voting system (Paatey, E \& Ofori, G.O., 2011). Electronic Voting (E-Voting) merupakan bagian dari e-government dengan jenis hubungan G2C (Government to Citizen), perkembangan ilmu pengetahun dan teknologi (IPTEK) sudah selayaknya dapat dimanfaatkan guna memajukan dan memudahkan aktivitas proses kebutuhan manusia baik yang sifatnya personal maupun interpersonal. E-voting telah digunakan di beberapa negara seperti Brazil (Avgerou, 2013), bahkan di Yordania (Nu'man, 2012).

Aplikasi teknologi untuk adopsi di berbagai bidang termasuk penerapannya untuk pesta demokrasi melalui e-voting memicu sejumlah keuntungan dan kelemahan, misalnya peluang sistem disusupi oleh pihak-pihak yang tidak bertangggungjawab, human error dan ancaman lainnya. Bahkan menurut penelitian yang dilakukan Oostveen (2009) mengidentifikasi risiko serius dari penerapan sistem e-voting untuk proses demokrasi, dan asumsi bahwa e-voting akan meningkatkan jumlah pemilih secara keseluruhan tidak didukung oleh penelitian yang telah mereka lakukan.

\section{Unified Theory of Acceptance and Use of Technology (UTAUT)}

Model UTAUT merupakan sebuah model berbasis teori yang dikembangkan oleh Vankatesh, et al. pada tahun 2003. Model ini menggambarkan berbagai faktor yang mempengaruhi penerimaan individu terhadap suatu teknologi informasi (Venkatesh, Zhang, \& Sykes, 2011). Misal teori ini diujikan untuk layanan internet banking didapati bahwa faktor perilaku penggunaan internet banking, yang paling penting adalah faktor niat perilaku untuk menggunakan internet banking itu sendiri (Martins, Oliveira, \& Popovič, 2014).

Dalam UTAUT terdapat empat variable/konstruk yang menjadi faktor penentu langsung yang bersifat signifikan terhadap penerimaan maupun penggunaan teknologi. Keempat variabel tersebut adalah performance expectancy, effort expectancy, social influence, dan facilitating condition. Terdapat pula empat moderator : gender, age, voluntariness, dan experience yang diposisikan untuk memoderasi dampak dari empat konstruk utama pada behavioral intention dan use behavior. Gambar 1 merupakan keterkaitan antaradeterminan-determinan dan moderator pendukung.

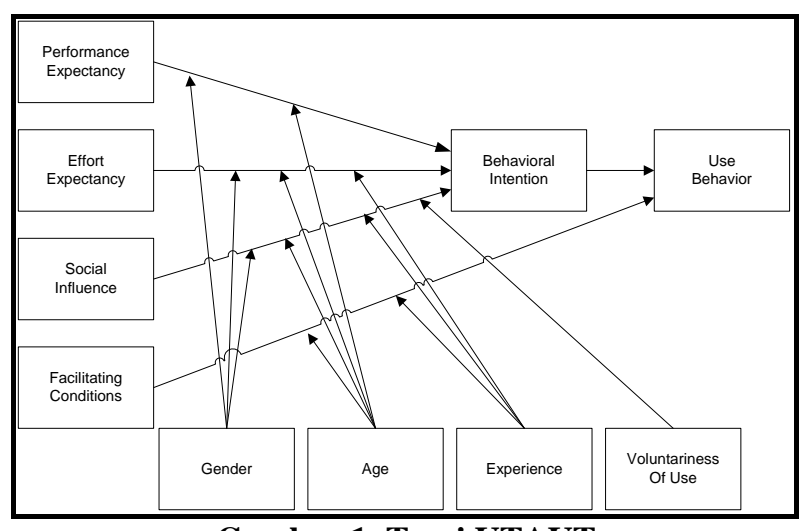

Gambar 1. Teori UTAUT

\section{III.METODE}

Berdasarkan permasalahan dan tujuan penelitian maka metode penelitian yang digunakan adalah metode deskriptif (descriptive research) dengan analisis korelasional yang membentuk analisis untuk menjawab pertanyaan pengaruh beberapa variable berdasarkan uji coba prototipe indo-vote.

\section{Variabel Penelitian}

Variabel dalam penelitian ini mencakup : (1) Performance expectancy merupakan tingkat keyakinan masyarakat bahwa penggunaan REVS akan membantu pemilih dalam menghasilkan performasi pemilu yang maksimal. (2) Effort expectancy digunakan sebagai derajat kemudahan dalam penggunaan sistem. (3) Facilitating condition merupakan tingkat dimana pemilih percaya bahwa sebuah organisasi dan infrastruktur teknis yang ada dapat mendukung 
penggunaan sistem. (4) Mobility merupakan kemudahan akses yang dapat mendukung penggunaan sistem. (5) Security \& privacy tingkat dimana kebutuhan akan sistem yang aman dan menjaga privasi pemilih dapat mendukung penggunaan sistem. (6) Experience merupakan pengalaman yang didapat langsung oleh pemilih setelah menggunakan sistem dapat mendukung penggunaan sistem. (7) Intention to use REVS tingkat penggunaan dan harapan pemilih terhadap sistem.

\section{Hipotesis}

Hipotesis menggambarkan hubungan apa yang ingin diketahui dalam penelitian. Hipotesis penelitian adalah sebagai berikut, (1) H1: Terdapat hubungan pengaruh positif antara performance expectancy yang dimiliki sistem terhadap niat penggunaan REVS. (2) H2 : Terdapat hubungan pengaruh positif antara effort expectancy yang dimiliki sistem terhadap penggunaan niat menggunakan REVS. (3) H3 : Terdapat hubungan pengaruh positif antara facilitating condition yang dimiliki sistem terhadap penggunaan niat menggunakan REVS. (4) H4 : Terdapat hubungan pengaruh positif antara mobility yang dimiliki sistem terhadap penggunaan niat menggunakan REVS. (5) H5 : Terdapat hubungan pengaruh positif antara security \& privacy yang dimiliki sistem terhadap penggunaan niat menggunakan REVS. (6) H6 : Terdapat hubungan pengaruh positif antara experience yang dimiliki sistem terhadap penggunaan niat menggunakan REVS.

\section{HASIL DAN PEMBAHASAN}

\section{Prototype Indo-vote}

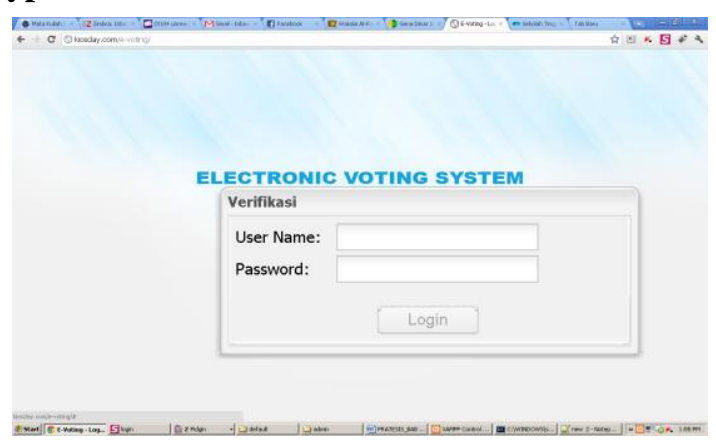

Gambar 2. Login System

Halaman login dan halaman proses pemilihan kandidat pada sistem Indo-vote.

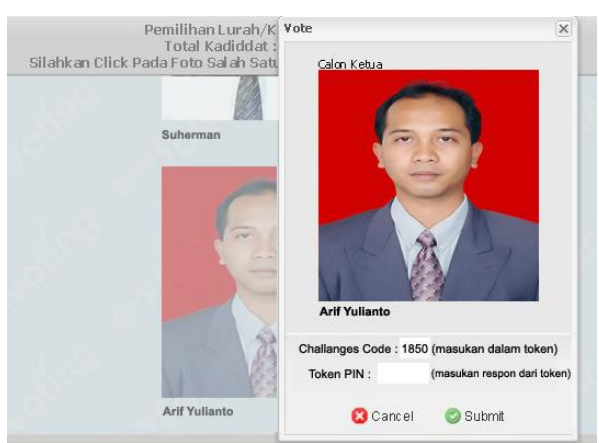

Gambar 3. Proses Pemilihan Kandidat

\section{Demografi Responden}

Kuesioner yang disebar kepada responden sebanyak 120 kuesioner dengan menggunakan metode purposive sampling. Data kuesioner yang dianggap layak digunakan berjumlah 100 , sebanyak 8 kuesioner tidak lengkap pengisiannya (missing data) dan 12 kuesioner tidak kembali sehingga kuesioner tersebut tidak dimasukan dalam analisis data. Penyebaran kuesioner disebar pula melalui alat bantu website kepada pihakpihak tertentu mengingat kesibukan mereka.

\section{Tabel 1. Daftar Kuesioner}

\begin{tabular}{ll}
\hline Kuesioner & Jumlah \\
\hline Kuesioner yang didistribusikan & 120 \\
\hline Kuesioner yang tidak kembali & $(12)$ \\
\hline Kuesioner yang tidak diisi lengkap & $(8)$ \\
\hline $\begin{array}{l}\text { Kuesioner yang layak digunakan untuk } \\
\text { keperluan analisis data }\end{array}$ & 100 \\
\hline
\end{tabular}

Tabel 2. Karakteristik Responden Berdasarkan Jenis Kelamin

\begin{tabular}{cccc}
\hline No & Jenis Kelamin & Jumlah & Persentase \\
\hline 1. & Pria & 58 & $58 \%$ \\
\hline 2. & Wanita & 42 & $42 \%$ \\
\hline & Jumlah & 100 & $100 \%$ \\
\hline
\end{tabular}

Tabel 3. Karakteristik Responden Berdasarkan Usia

\begin{tabular}{cccr}
\hline No & Umur (Tahun) & Jumlah & Persentase \\
\hline 1. & $18-24$ & 40 & $40 \%$ \\
\hline 2. & $25-44$ & 53 & $53 \%$ \\
\hline 3. & $45-59$ & 7 & $7 \%$ \\
\hline & Jumlah & 100 & $100 \%$ \\
\hline
\end{tabular}

Tabel 4. Karakteristik Responden Berdasarkan Tingkat Pendidikan

\begin{tabular}{cccr}
\hline No & $\begin{array}{c}\text { Tingkat } \\
\text { Pendidikan }\end{array}$ & $\begin{array}{c}\text { Jumlah } \\
\text { (orang) }\end{array}$ & Persentase \\
\hline 1. & SMP & 2 & $2 \%$ \\
\hline 2. & SMA & 36 & $36 \%$ \\
\hline 3 & DII/DIII/DIV & 13 & $13 \%$ \\
\hline 4 & S1/S2/S3 & 49 & $49 \%$ \\
\hline & Jumlah & 100 & $100 \%$ \\
\hline
\end{tabular}

Tabel 5. Karakteristik Responden Berdasarkan Media Pengguna

\begin{tabular}{cccr}
\hline No & Media / Perangkat IT & Jumlah & Persentase \\
\hline 1. & PC Desktop & 41 & $41 \%$ \\
\hline 2. & Laptop/notebook & 36 & $36 \%$ \\
\hline 3 & $\begin{array}{c}\text { Gadget (Blackberry, PDA, } \\
\text { handphone) }\end{array}$ & 23 & $23 \%$ \\
\hline & Jumlah & 100 & $100 \%$
\end{tabular}

Tabel 6. Karakteristik Responden Berdasarkan Pengalaman Pengguna Perangkat IT

\begin{tabular}{cccr}
\hline No & $\begin{array}{c}\text { Pengalaman Pengguna } \\
\text { Perangkat IT }\end{array}$ & $\begin{array}{c}\text { Jumlah } \\
\text { (orang) }\end{array}$ & Persentase \\
\hline 1. & $0-10$ tahun & 40 & $40 \%$ \\
\hline 2. & $11-20$ tahun & 44 & $44 \%$ \\
\hline 3. & Lebih dari 21 tahun & 16 & $16 \%$ \\
\hline & Jumlah & 100 & $100 \%$ \\
\hline
\end{tabular}


Tabel 7. Karakteristik Responden Berdasarkan Aktifitas Pemilu (boleh lebih dari satu)

\begin{tabular}{ccc}
\hline No & $\begin{array}{c}\text { Pengalaman Pemilihan Tahun } \\
\text { lalu }\end{array}$ & Jumlah \\
\hline 1. & Pemilih & 75 \\
\hline 2. & Panitia Pemilu & 4 \\
\hline 3. & Saksi Pemilu & 9 \\
\hline 4. & Tidak Berpartisipasi & 14 \\
\hline & Jumlah & 102 \\
\hline
\end{tabular}

Tabel 8. Karakteristik Responden Berdasarkan Lokasi Penggunaan Internet

\begin{tabular}{cccc}
\hline No & $\begin{array}{c}\text { Lokasi Penggunaan } \\
\text { Internet }\end{array}$ & Jumlah & Persentase \\
\hline 1. & Rumah & 25 & $25 \%$ \\
\hline 2. & Warnet & 12 & $12 \%$ \\
\hline 3. & Kantor & 30 & $30 \%$ \\
\hline 4. & Sekolah/Kampus & 25 & $25 \%$ \\
\hline 5. & Café & 8 & $8 \%$ \\
\hline \multicolumn{4}{c}{ Jumlah } \\
\hline
\end{tabular}

\section{Deskripsi Data Penelitian}

Deskripsi data penelitian bertujuan untuk memudahkan pemahaman terhadap hasil penelitian. Deskripsi data penelitian dilakukan secara berturut-turut dari data variabel sikap Effort Expectancy (X1), Facilitating Condition (X2), Mobility (X3), Performance Expectancy (X4), Security \& Privacy (X5) dan Experience (X6). Dari perhitungan data diperoleh skor tertinggi, skor terendah, rata-rata dan standar deviasi sebagaimana terlihat pada Tabel 9.

Tabel 9 Deskripsi Data

\begin{tabular}{|c|c|c|c|c|c|c|}
\hline Variabel & $\mathbf{N}$ & Min & Max & Mean & Median & SD \\
\hline $\begin{array}{c}\text { Effort } \\
\text { Expectanc } \\
y\end{array}$ & 100 & 4 & 24 & 19,08 & 19,00 & 3,639 \\
\hline $\begin{array}{c}\text { Facilitatin } \\
g \\
\text { Condition } \\
\end{array}$ & 100 & 3 & 18 & 13,61 & 13,00 & 3,152 \\
\hline Mobility & 100 & 3 & 18 & 14,61 & 14,00 & 2,817 \\
\hline $\begin{array}{c}\text { Performa } \\
\text { nce } \\
\text { Expectanc } \\
y\end{array}$ & 100 & 3 & 18 & 13,51 & 13,00 & 2,999 \\
\hline $\begin{array}{c}\text { Security \& } \\
\text { Privacy }\end{array}$ & 100 & 3 & 18 & 13,68 & 13,00 & 2,974 \\
\hline Experience & 100 & 3 & 18 & 14,36 & 14,00 & 2,826 \\
\hline
\end{tabular}

\section{Pengujian SEM dengan smartPLS}

Kuadrat terkecil parsial (PLS) pendekatan untuk pemodelan persamaan struktural (SEM) telah diadopsi secara luas dalam bidang penelitian bisnis seperti sistem informasi, perilaku konsumen, dan pemasaran (Peng, 2012). Analisis dengan pendekatan PLS, dilakukan dengan mengevaluasi measurement model (outer model) dan structural model (inner model). Penggunaan partial least square $(P L S)$ dapat dijadikan alternative dalam pengujian hipotesis (Hair, 2011), hal tersebut dilakukan sesuai dengan tujuan awal dari penelitian yaitu untuk menguji hubungan antar variabel yang digunakan dalam penelitian karena PLS-SEM membutuhkan beberapa pilihan penting yang jika tidak dilakukan dengan benar dapat menyebabkan temuan yang tidak tepat, interpretasi, dan kesalahan dalam menyimpulkan (Hair, 2011).

\section{Analisis Measurement Model (Outer Model)}

Tahap awal adalah dengan membuat model penelitian atau biasa disebut path diagram. Melalui path diagram hubungan antar variabel dependen dan independen dapat terlihat dengan jelas seperti terlihat pada Gambar 4.

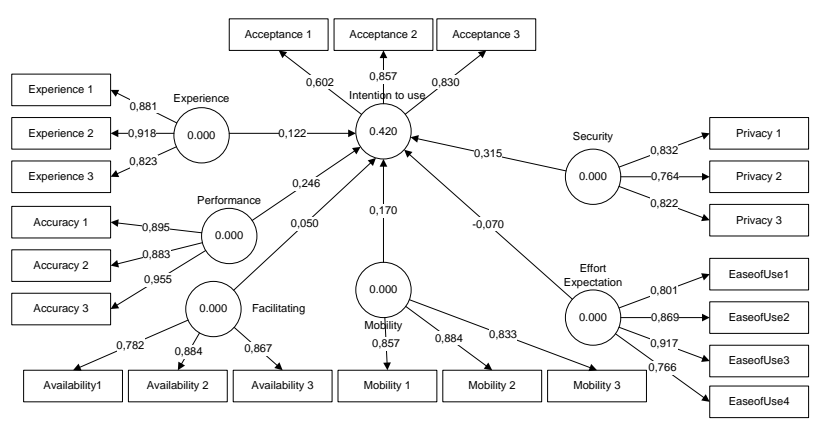

Gambar 4. Path Diagram

Setelah model ditetapkan, tahapan selanjutnya adalah pengujian measurement model dengan pendekatan PLS, tiga tahapan yang harus dilakukan dapat dijelaskan sebagai berikut : (1) Pengujian individual item reliability. Berdasarkan skema output path diagram pada Gambar 4, dapat dilihat bahwa tidak ada indikator yang perlu dieliminasi karena seluruh indikator memiliki nilai factor loading > 0,50. (2) Pengujian internal consistency. Nilai composite reliability dan cronbach's alpha dari model penelitian, dapat dilihat pada Tabel 10. Kriteria validitas dan reliabilitas dapat dilihat dari nilai reliabilitas suatu konstruk dan nilai Average Variance Extracted (AVE) dari masing-masing konstruk. Konstruk yang memiliki reliabilitas tinggi jika nilainya $>0,70$ dan AVE berada diatas 0,50 .

Tabel 10. Quality Criteria

\begin{tabular}{|c|c|c|c|c|}
\hline & AVE & $\begin{array}{l}\text { Composite } \\
\text { Reliability }\end{array}$ & $\begin{array}{c}\boldsymbol{R} \\
\text { Square }\end{array}$ & $\begin{array}{c}\text { Cronbachs } \\
\text { Alpha }\end{array}$ \\
\hline $\begin{array}{c}\text { Effort } \\
\text { Expectancy }\end{array}$ & 0,7064 & 0,9055 & & 0,8592 \\
\hline $\begin{array}{c}\text { Facilitating } \\
\text { Condition }\end{array}$ & 0,7145 & 0.8822 & & 0.8059 \\
\hline Mobility & 0,7363 & 0.8933 & & 0.8206 \\
\hline $\begin{array}{c}\text { Performance } \\
\text { Expectancy }\end{array}$ & 0,8311 & 0.9365 & & 0.8977 \\
\hline $\begin{array}{c}\text { Security \& } \\
\text { Privacy }\end{array}$ & 0,6504 & 0.8479 & & 0.7312 \\
\hline Experience & 0,7653 & 0.9071 & & 0.8468 \\
\hline $\begin{array}{c}\text { Intention to } \\
\text { use REVS }\end{array}$ & 0,5951 & 0.8117 & 0,4197 & 0.6861 \\
\hline
\end{tabular}

Tabel diatas menjelaskan bahwa nilai composite reliability dan nilai AVE setiap variabel lebih besar dari 0,70 sebagai cut-off value-nya, sehingga dapat 
disimpulkan bahwa semua konstruk memenuhi kriteria reliabel dan valid. Sedangkan untuk nilai cronbach's alpha, hanya ada satu variabel yang nilainya dibawah nilai yang direkomendasikan ( $>0,70)$, yaitu variabel use behavior, namun nilai tersebut hanya berbeda sedikit dengan nilai rekomendasi. Oleh karena itu, internal consistency dapat disimpulkan telah terpenuhi.

Pada pengujian ini, syarat pertama yang harus terpenuhi adalah nilai AVE dimana harus lebih besar dari 0,50 (Udeh, 2008). Pada Tabel 6 bisa telihat bahwa nilai AVE seluruh variabel $>0,50$ sehingga syarat pertama telah terpenuhi. Untuk tahap selanjutnya yang harus terpenuhi adalah nilai akar kuadrat dari AVE setiap variabel, harus lebih besar daripada nilai korelasi dengan variabel lainnya (Udeh, 2008). Tabel 11 merupakan nilai akar kuadrat AVE (angka dengan tanda “*” yang berada pada posisi diagonal) setiap variabel, harus lebih besar daripada nilai korelasi variabel lainnya (angka yang posisinya dalam satu baris dan satu kolom antar variabel merupakan hasil pembulatan nilai korelasi pada tabel output SmartPLS latent variabel correlation. Dengan hasil tersebut, model penelitian sudah memenuhi discriminant validity. dengan AVE variabel yang bersesuaian). Nilai korelasi

Tabel 12. Nilai $R$-square

\begin{tabular}{c}
\hline \\
\hline Rffort Expectancy \\
\hline Facilitating Condition \\
\hline Mobility \\
\hline Performance Expectancy \\
\hline Security \& Privacy \\
\hline Experience \\
\hline Intention to Use REVS
\end{tabular}

\section{Pengujian Hipotesis}

Pengujian hipotesis didasarkan pada nilai yang terdapat pada output result for inner weight. Tabel 13 memberikan output estimasi untuk pengujian model struktural.

\section{Tabel 13. Result For Inner Weight}

\begin{tabular}{ccccc}
\hline & $\begin{array}{c}\text { Original } \\
\text { Sample } \\
\text { Estimate } \\
(\mathbf{O})\end{array}$ & $\begin{array}{l}\text { Mean of } \\
\text { Sub } \\
\text { samples } \\
(\mathbf{M})\end{array}$ & $\begin{array}{l}\text { Standard } \\
\text { Deviation } \\
\text { (STEDEV) }\end{array}$ & $\begin{array}{c}\text { T-Statistics } \\
(\mid \mathbf{O} \text { STER } \\
\text { R|) }\end{array}$ \\
\hline EE -> IU & $-0,0695$ & $-0,0892$ & 0,1484 & 0,4687 \\
\hline FC -> IU & 0,0502 & 0,0669 & 0,1080 & 0,4645 \\
\hline MB -> IU & 0,1703 & 0,1709 & 0,0908 & 1,8760 \\
\hline PE -> IU & 0,2458 & 0,2578 & 0,1239 & 1,9835 \\
\hline SP -> IU & 0,3148 & 0,3124 & 0,1223 & 2,5726 \\
\hline VU -> IU & 0,1216 & 0,0964 & 0,1139 & 1,0682
\end{tabular}

Tabel 11. Korelasi Latent Variable

\begin{tabular}{|c|c|c|c|c|c|c|c|}
\hline & $\mathbf{E E}$ & $\mathbf{E X}$ & FC & IU & MB & $\mathbf{P E}$ & Tingkat signifikansi path coefficient didapat dari \\
\hline $\mathbf{E E}$ & $1.000 *$ & & & & & & menjalankan \\
\hline $\mathbf{E X}$ & 0.660 & $0.812^{*}$ & & & & & yang digunakan untuk \\
\hline FC & 0.695 & 0.493 & $0.702^{*}$ & & & & diterima atau ditolaknya hipotesis yang diajukan. \\
\hline IU & 0.438 & 0.422 & 0.341 & $0.584^{*}$ & & & Tingkat signifikansi 0,05 , hipotesis akan diterima \\
\hline MB & 0.613 & 0.385 & 0.513 & 0.476 & $0.689 *$ & & apabila $t$-value melebihi titik kritis sebesar 1,645 . Tabel \\
\hline PE & 0.623 & 0.443 & 0.450 & 0.527 & 0.589 & $0.768 *$ & upakan rangkuman dari hasil pengujian hipotes \\
\hline SP & 0.428 & 0.473 & 0.269 & 0.542 & 0.415 & 0.471 & dekatan P S S \\
\hline
\end{tabular}

Setelah melakukan seluruh pengujian measurement model diatas, telah terbukti bahwa penelitian sudah memenuhi persyaratan seluruh tahapan pengujian. Kesimpulan yang didapat dari pengujian diatas yaitu proses pengujian structural model sudah dapat dilakukan. Pengujian structural model dimaksudkan untuk menentukan diterima atau tidaknya hipotesis yang diajukan.

\section{Analisis Structural Model (Inner Model)}

Pengujian inner model atau struktural model dimaksudkan untuk melihat hubungan antar konstruk, nilai signifikansi dan $R$-square model penelitian. Inner model dievaluasi dengan menggunakan $R$-square untuk konstruk dependen uji-t dan signifikansi koefisien parameter jalur struktural.

Nilai $\mathrm{R}^{2}$ merupakan hasil evaluasi model penelitian dapat dilihat pada Tabel 12. Variabel use behavior menjelaskan nilai $\mathrm{R}^{2}$ sebesar 0,419 yang artinya $41,9 \%$ variance dari use behavior dipengaruhi oleh independent variables. Nilai tersebut telah memenuhi nilai yang direkomendasikan, yaitu 0,40 s.d 0,60 (Udeh, 2008).

\begin{tabular}{|c|c|c|c|}
\hline & $\begin{array}{c}\text { Path } \\
\text { Coefficient }\end{array}$ & $\begin{array}{c}\text { T- } \\
\text { Value }\end{array}$ & Ket \\
\hline $\begin{array}{l}\text { Effort Expectancy -> } \\
\text { Intention to Use REVS }\end{array}$ & $-0,0695$ & 0,4433 & $\begin{array}{c}\text { Tidak } \\
\text { signifikan }\end{array}$ \\
\hline $\begin{array}{l}\text { Facilitating Condition -> } \\
\text { Intention to Use REVS }\end{array}$ & 0,0502 & 0,4301 & $\begin{array}{c}\text { Tidak } \\
\text { signifikan }\end{array}$ \\
\hline $\begin{array}{c}\text { Mobility -> Intention to Use } \\
\text { REVS }\end{array}$ & 0,1703 & 2,1579 & Signifikan \\
\hline $\begin{array}{c}\text { Performance Expectancy -> } \\
\text { Intention to Use REVS }\end{array}$ & 0,2458 & 1,8905 & Signifikan \\
\hline $\begin{array}{l}\text { Security \& Privacy -> } \\
\text { Intention to Use REVS }\end{array}$ & 0,3148 & 2,7132 & Signifikan \\
\hline $\begin{array}{c}\text { Experience -> Intention to } \\
\text { Use REVS }\end{array}$ & 0,1216 & 1,0900 & $\begin{array}{c}\text { Tidak } \\
\text { Signifikan }\end{array}$ \\
\hline
\end{tabular}

Berdasarkan hasil uji structural model yang terdapat pada Tabel 14, dapat disimpulan sebagai berikut : (1) Hipotesis bahwa effort expectancy berpengaruh terhadap Intention to Use REVS ditolak. (2) Hipotesis bahwa facilitating condition berpengaruh terhadap Intention to Use REVS ditolak. (3) Hipotesis bahwa mobility berpengaruh terhadap Intention to Use REVS terbukti signifikan dengan koefisien sebesar 0,1703. Oleh karena itu hipotesis ini diterima. (4) Hipotesis bahwa performance expectancy berpengaruh terhadap Intention to Use REVS terbukti signifikan dengan koefisien sebesar 0,2458. Oleh karena itu hipotesis ini diterima. 
(5) Hipotesis bahwa security \& privacy berpengaruh terhadap Intention to Use REVS terbukti signifikan dengan koefisien sebesar 0,3148. Oleh karena itu hipotesis ini diterima. (6) Hipotesis bahwa experience berpengaruh terhadap Intention to Use REVS ditolak.

\section{PENUTUP}

\section{Kesimpulan}

Penelitian ini bertujuan untuk melihat pengaruh penerapan teknologi REVS terhadap tingkat partisipasi masyarakat berdasarkan prototipe $e$-voting yang sudah dibuat yaitu indo-vote. Beberapa variabel diuji dengan menggunakan teknik analisis Partial Least Square (PLS) atau biasa disebut variance based SEM, tools yang digunakan untuk menganalisis hubungan antar variabel tersebut, menggunakan SmartPLS 2.0. Berdasarkan hasil analisis dan pembahasan pada bagian sebelumnya, maka dapat disimpulkan bahwa penggunaan model UTAUT yang terdiri dari faktor performance expectancy, mobility dan security \& privacy telah terbukti dapat mempengaruhi diterimanya sistem REVS oleh pemilih. Namun variabel effort expectancy, facilitating condition dan experience tidak mempengaruhi penerimaan sistem REVS.

\section{Saran}

Untuk penelitian-penelitian selanjutnya perlu dipertimbangkan beberapa saran, berikut saran-saran yang perlu dipertimbangkan: (1) Jenis pemilihan lebih diperluas lagi seperti pemilihan kepala daerah, anggota legislatif tingkat daerah atau pusat, dan pemilihan presiden dan wakil presiden, namun sebelumnya perlu dilakukan penyesuaian terhadap faktor seperti hukum, sosial, dan prosedur operasional. (2) Uji coba penggunakan teknologi $e$-voting bisa menggunakan model lain dari jenis $e$-voting itu sendiri, seperti direct remote evoting (DRE) atau e-voting berbasiskan TPS. Melalui jenis ini, masyarakat yang minim akan teknologi pun dapat mencoba simulasi proses pemilu secara langsung. Pemilihan jenis e-voting disesuaikan dengan letak geografis, infrastruktur IT dan perangkat pendukung seperti listrik dan saluran komunikasi data yang handal.

\section{VI.DAFTAR PUSTAKA}

[1] Avgerou, C. (2013). Explaining Trust in ITMediated Elections : A Case Study of E-Voting in Brazil. Journal of the Association for Information systems, 14(8), 420-451.

[2] Edi, P \& Fereshti N. (2010). E-Voting : Urgensi Transparansi dan Akuntabilitas, Seminar Nasional Informatika (SEMNASIF), Vol 1, No 5 (2010):

Information system And Application.

[3] Hair, J. F., Sarstedt, M., Ringle, C. M., \& Mena, J. (2011). An assessment of the use of partial least squares structural equation modeling in marketing research. Journal of the Academy of Marketing Science, 40(3), 414-433.

[4] Martins, C., Oliveira, T., \& Popovič, A. (2014). Understanding the Internet banking adoption: A unified theory of acceptance and use of technology and perceived risk application. International Journal of Information Management, 34(1), 1-13. http://doi.org/10.1016/j.ijinfomgt.2013.06.002

[5] Nu'man, A. (2012). A Framework for Adopting EVoting in Jordan. Electronic Journal of $e$ Government, 10(2), 133-146. Retrieved from http://www.ejeg.com/issue/download.html?idArticl $\mathrm{e}=252$

[6] Oostveen, A.-M. (2009). Users' experiences with e-voting: a comparative case study. International Journal of Electronic Governance, 2(4), 357-377. http://doi.org/10.1504/IJEG.2009.030527

[7] Paatey, E., \& Ofori-Dwumfuo, G. O. (2011). The design of an electronic voting system. Research Journal of Information Technology, 3(2), 91-98.

[8] Peng, D. X., \& Lai, F. (2012). Using partial least squares in operations management research: A practical guideline and summary of past research. Journal of Operations Management, 30(6), 467480.

[9] Prevost, Alicia Kolar, and Brian F. Schaffner. "Digital divide or just another absentee ballot? Evaluating Internet voting in the 2004 Michigan Democratic primary." American Politics Research 36.4 (2008): 510-529.

[10] Venkatesh V, Zhang X and Sykes T A (2011) "Doctors do too little technology : a longitudinal field study of an electronic healthcare”. Journal Information systems Research. Volume: 22 Issue: 3 pp.523-546

[11] Yakub. 2012. Pengantar Sistem Informasi. Yogyakarta: Graha Ilmu.

[12] Yusof, M. M., Kuljis, J., Papazafeiropoulou, A., \& Stergioulas, L. (2008). An evaluation framework for Health Information systems: human, organization and technology-fit factors (HOT-fit). International Journal of Medical Informatics, 77(6),386-98. http://doi.org/10.1016/j.ijmedinf.2007.08.011 